\title{
AÇÕES DIDÁTICO-ADMINISTRATIVAS DURANTE A PANDEMIA: RESULTADO DE PESQUISA DO GT FORMAÇÃO DE PROFESSORES DA ABENGE
}

\section{DOI: $10.37702 / 2175-957 X . C O B E N G E .2021 .3603$}

Jose Aquiles Baesso Grimoni - jose.grimoni@usp.br

Universidade de Sao Paulo

Rua Pereira do Lago - 360158

05590-000 - Sao Paulo - SP

Octavio Mattasoglio Neto - omattasoglio@uol.com.br

Instituto Mauá de Tecnologia

Rua Tijuco Preto 933

03316-000 - São Paulo - SP

Angelo Eduardo Battistini Marques - angeloebm@gmail.com Instituto Mauá de Tecnologia

Rua Fausto 404

04285-080 - São Paulo - SP

Renata dos Santos - renatasantos@unifei.edu.br Universidade Federal de Itajubá

Rua São Marcos 162

35930-116 - João Monlevade - MG

Terezinha Severino da Silva - terezinha.silva@uftm.edu.br Universidade Federal do Triângulo Mineiro

Rua Dr Mário de Almeida Franco 1069

38046-320 - Iturama - MG

Tatiana Bittencourt Dumêt - tbdumet@ufba.br

Universidade Federal da Bahia

Rua Prof. Aristides Novis 2

40210-630 - Salvador - BA

Fransuze dos Santos Oliveira - fransuzeoliveira@gmail.com CESUPA

Av. José Malcher 1701 


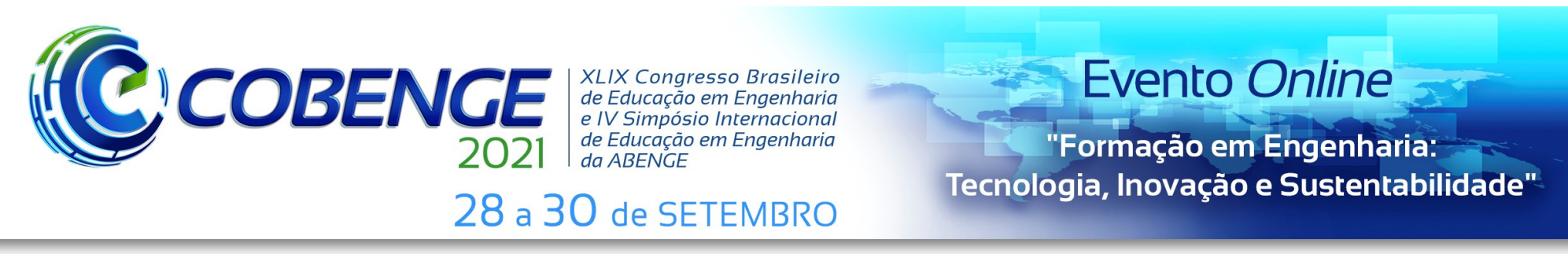

66060-230 - Belém - PA

Resumo: Este estudo apresenta os resultados parciais da pesquisa realizada pelo Grupo de Trabalho de Formação de Professores da Abenge sobre como as instituições de ensino superior atuaram durante a suspensão das atividades presenciais devido à pandemia. Responderam à pesquisa 79 instituições, sendo 33 universidades públicas federais, 8 universidades públicas estaduais, 12 confessionais, 25 instituições privadas e 1 do Sistema S. Como principal resultado, identificou-se que as instituições se adaptaram ao novo contexto a partir da utilização de plataformas e ferramentas diferenciadas com foco no desenvolvimento das atividades didático-administrativas.

Palavras-chave: Formação de professores. Ensino Superior. Ensino Remoto. Levantamento. Educação mediada pela tecnologia. 


\section{AÇÕES DIDÁTICO-ADMINISTRATIVAS DURANTE A PANDEMIA: RESULTADO DE PESQUISA DO GT FORMAÇÃO DE PROFESSORES DA ABENGE}

\section{INTRODUÇÃO}

Com o avanço da pandemia ocasionada pela Covid-19, os professores se viram desafiados à reinvenção, surgindo oportunidades para esses profissionais utilizarem novas ferramentas de ensino, até então pouco utilizadas na prática docente, instigando-os a refletir velhos hábitos e a repensar suas aulas. Cada Instituição de Ensino Superior (IES) passou a adotar uma educação virtual, o que gerou alguns questionamentos, dentre eles o de estarem preparados para apoiar e envolver milhares de alunos em um novo ambiente de aprendizagem, em um período de tempo muito curto. As instituições de ensino precisaram se adaptar de forma que as atividades passassem a ser desenvolvidas em coerência ao novo contexto.

Nesta pesquisa, ainda em vigência, o principal objetivo é fazer um levantamento de como a formação de professores tem sido realizada nas instituições e como essa nova realidade do ensino a distância afetou e afetará os cursos de Engenharia no futuro. Este estudo faz parte das atividades desenvolvidas pelo Grupo de Trabalho de Formação de Professores da Associação Brasileira de Educação em Engenharia (Abenge), que, em 2020, dedicou esforços para refletir, principalmente, sobre a formação docente no contexto da pandemia.

Por meio de um formulário on-line enviado às instituições de ensino, de maio a julho de 2020, 79 instituições de 20 Estados do Brasil responderam perguntas, que abordavam desde a identificação/ natureza da IES até o formato das capacitações desenvolvidas.

Neste documento, serão apresentados e discutidos os principais resultados parciais desta pesquisa, confirmando uma verdade abordada em outros estudos (MISLEH, 2020; NHANTUMBO, 2020), a saber: a deficiente preparação dos professores para lecionar em atividades remotas.

\section{REFERENCIAL TEÓRICO}

A situação da pandemia levou as escolas a adotarem ações de apoio aos seus professores em diversas dimensões, desde a preparação para o uso de ferramentas no ensino remoto, passando pela formação continuada em estratégias ativas para promover a aprendizagem, até aquelas voltadas para o bem-estar físico e mental do professor. Os docentes precisaram mudar às pressas para as atividades remotas, incluindo à prática didática recursos adicionais, principalmente tecnológicos. Foram necessários treinamentos para lecionar em instrução remota bem como recorrer a estratégias para motivar os discentes e minimizar o impacto negativo na aprendizagem, corroborado pelas desigualdades sociais que passaram a se mostrar mais evidentes.

Há vários estudos que exemplificam tal mudança, como o de Azevedo, Mattasoglio Neto e Fonseca (2020) e o de Nakao e Grimoni (2020). A partir de um relato de experiências, Azevedo, Mattasoglio Neto e Fonseca (2020) apresentam as discussões realizadas em encontros semanais on-line com os docentes cujo lema era "isolado, mas não sozinho", numa referência à necessidade de um acolhimento docente nesse período 
de súbito isolamento social. Reuniões com esse objetivo não são comuns no ensino superior, no entanto o trabalho alcançou um resultado positivo pelo compartilhamento de experiências e aproximação dos professores. Por sua vez, Nakao e Grimoni (2020) socializaram uma experiência que iniciou presencialmente, antes do isolamento, e teve sequência de forma remota com uso do Google Meet. Considerando que o projeto desenvolvido na disciplina Introdução à Engenharia Civil tinha o objetivo de detectar pontos positivos e negativos nos espaços e propor soluções para patologias e melhorias nas condições de conforto e eficiência por meio de projetos com a vertente de sustentabilidade, a solução encontrada foi consultar os alunos que estavam há mais tempo no prédio em estudo. A coleta dos dados foi feita a partir de questionários respondidos pelos alunos e pelos professores que identificaram a percepção nos diversos aspectos, avaliando os pontos fortes e fracos para uma melhoria contínua dos ambientes, e a possível adoção de novas soluções após o isolamento social.

Nas experiências supracitadas, ficou evidente a necessidade de saber lidar com a tecnologia e as várias possibilidades educacionais que ela permite (plataformas e softwares de usos síncronos e assíncronos). Para se conectar com os discentes, foram necessários treinamentos urgentes, realizados por conta própria ou por indicação da IES, cuja principal finalidade era se preparar para o trabalho remoto de forma a não prejudicar a aprendizagem e tendo foco na continuidade da oferta de um ensino de qualidade, mesmo diante de tantas incertezas provocadas pelo contexto.

De acordo com Hobold e Matos (2010), incorporar essas novas tecnologias educacionais exige do professor universitário constantes atualizações, assim como também qualificação e formação permanente. Isso, inclusive, ficou bem acentuado com a pandemia. O processo de formação continuada dos professores requer o uso de estratégias que assegurem a aprendizagem dos discentes, bem como o domínio da ferramenta tecnológica. Assim, a inserção de tecnologias educativas nas aulas propicia um ambiente inovador, favorece o enriquecimento do ensino e, também, a mudança de postura dos envolvidos no processo.

Em meio aos desafios, por exemplo: a garantia das aulas práticas e de laboratório na forma remota, há considerações positivas, como as relatadas por Kuhfeld et al. (2020). Os autores realizaram um estudo com o objetivo de compreender e projetar como o fechamento das escolas poderia afetar o desempenho e o crescimento dos discentes em 2019-2020 e em 2020-2021. Como resultado do fechamento das escolas, a pesquisa de Kuhfeld et al. (2020) identificou alguns pontos negativos, a saber: retorno presencial dos discentes com variabilidade nas habilidades acadêmicas, impacto no desempenho dos discentes e defasagem na aprendizagem deles. Mesmo assim, os autores também identificaram, pelas projeções, que haverá ganho em leitura, mesmo não tendo tanta clareza da eficácia do aprendizado remoto. Eles ainda consideraram que os resultados apresentados farão parte de um conjunto de estudos relevantes para capacitar líderes escolares e pesquisadores, dentre outras lideranças, na tomada de decisões urgentes, baseadas em evidência, frente a contextos semelhantes ao da Covid-19.

Diante da sinalização da preparação deficiente dos docentes para lecionar em atividades remotas, como apontado por Misleh (2020) e Nhantumbo (2020), é preciso ter consciência de que o conhecimento de determinada ferramenta ou uso dela, por meio de simples e rápidos cursos, tão somente, não resolverá o problema da educação. É preciso que o professor se mantenha informado e atualizado, buscando possibilidades de uso das tecnologias que possam agregar em suas práticas pedagógicas. O professor precisa refletir sobre como um determinado conteúdo pode ser ensinado com o uso da tecnologia, e também como o aluno pode aprender melhor com o uso de diferentes ferramentas. $E$ 
mais: a natureza da aprendizagem de um conceito pode mudar dependendo do recurso com que o professor abordar o assunto.

\section{MATERIAIS E MÉTODOS}

Esta pesquisa, realizada por meio de levantamento, foi desenvolvida de forma remota com a coleta de dados em duas etapas. A primeira ocorreu de maio a julho de 2020 e foi direcionada a várias instituições de ensino de diversas regiões do Brasil. A segunda, em vigência desde maio de 2021, foi direcionada às 79 instituições respondentes da primeira etapa. Para ambas, a coleta de dados ocorreu por meio de formulário on-line do Google Workspace.

Para que a amplitude das respostas correspondesse a várias regiões do Brasil, o formulário foi enviado para o e-mail de várias instituições, conforme banco de dados da Abenge, além de ser disponibilizado durante uma das lives realizadas pelo Grupo de Trabalho de Formação de Professores da Abenge. Convém destacar que as lives tiveram alcance em todo o Brasil e no exterior.

No formulário, constam seis seções, a saber: identificação, continuidade dos trabalhos, plataformas e recursos, relacionamento com os discentes, formação e treinamento bem como capacitação docente. $\mathrm{Na}$ identificação, procurou-se verificar a natureza da IES (pública, privada, confessional ou Sistema $\mathrm{S}$ ), número de cursos de Engenharia e número de docentes e discentes. Na continuidade dos trabalhos, verificouse como ocorreu a parada e a retomada das atividades em ambiente remoto. Em relação a plataformas e recursos, o objetivo foi identificar os recursos tecnológicos usados pelos docentes nas atividades educacionais em ambiente remoto. No item relacionamento com os discentes, foram identificadas as estratégias para manter o engajamento discente, bem como identificar métodos e processos de avaliação de desempenho acadêmico. Para a formação e treinamento, buscou-se detectar as principais dificuldades de docentes e discentes nessa mudança para o ambiente remoto. Por fim, em capacitação docente, identificou-se o tipo de treinamento que as instituições ofereceram aos professores para a migração às novas condições dos trabalhos de ensino e aprendizagem.

A tabulação ocorreu em julho de 2020 cujos resultados estão expostos na seção 4 deste artigo e serão utilizados, em oportunidade futura, para realizar um comparativo com os dados da segunda etapa, ainda em fase de coleta.

\section{$4 \quad$ PRINCIPAIS RESULTADOS E ANÁLISES}

Inicialmente, considerando que o direcionamento do formulário foi de amplitude aberta, ou seja, sem quantitativo específico de destinatário, buscou-se identificar o público respondente a partir do questionamento sobre a natureza da IES cujo resultado (Gráfico 1) apresentou $42 \%$ vinculados às instituições públicas federais. Importante destacar que, diante do cenário apresentado à época, infere-se que uma parcela significativa das instituições, independente da natureza, paralisou suas atividades presenciais, considerando que houve respondentes de 20 Estados brasileiros. 
Gráfico 1 - Natureza das IES que responderam à pesquisa

Natureza

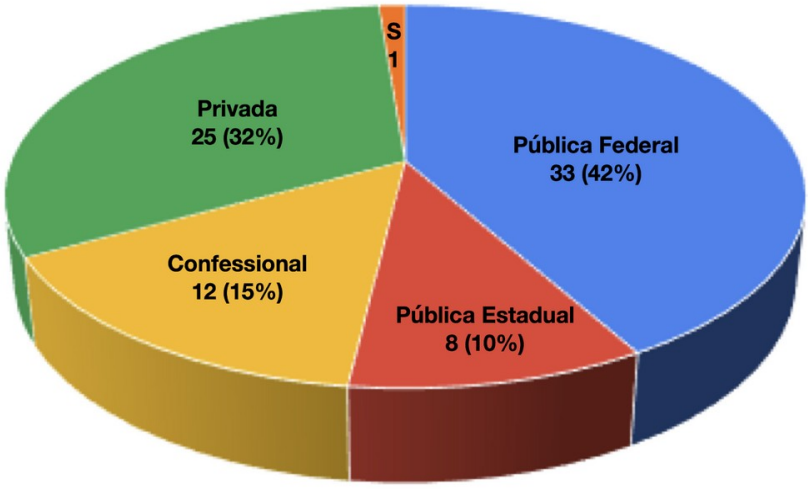

Fonte: Autores deste estudo

No momento da pesquisa, algumas instituições ainda estavam com as atividades suspensas, sobretudo Universidades e Institutos Federais. O Gráfico 2 mostra o status das IES em relação à pausa e tempo de retomada com atividades on-line e remotas.

Gráfico 2 - Status da pausa ou tempo de retomada de atividades das IES

PAUSA E RETOMADA
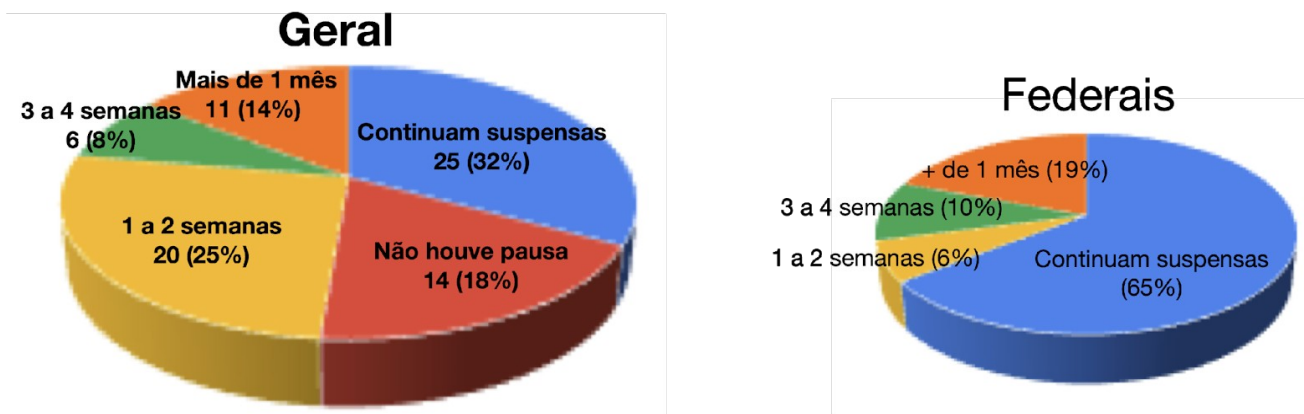

Privadas
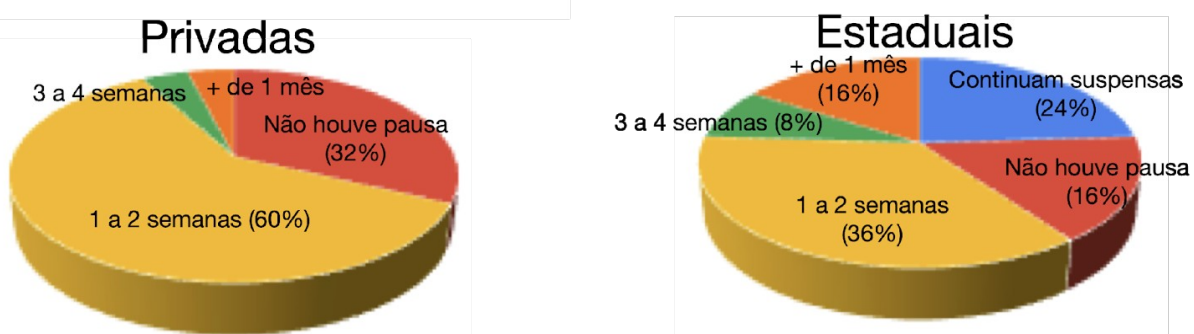

Fonte: Autores deste estudo

Outra questão abordou quais plataformas e recursos tecnológicos foram e estão sendo utilizados pelas IES na retomada das atividades na modalidade on-line. Conforme apontado no Gráfico 3, há um número expressivo sem resposta (35\%), considerando que, à época de realização da pesquisa, várias instituições não haviam retomado suas atividades. 
Gráfico 3 - Plataforma e recursos tecnológicos utilizados na retomada on-line

\section{PLATAFORMA}

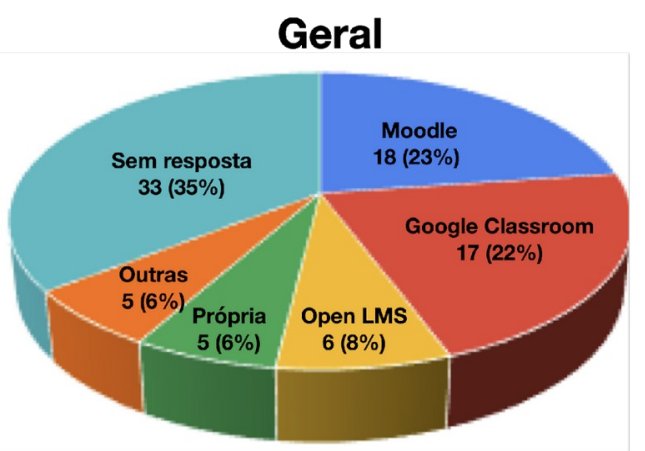

\section{Públicas (Federais e Estaduais)}

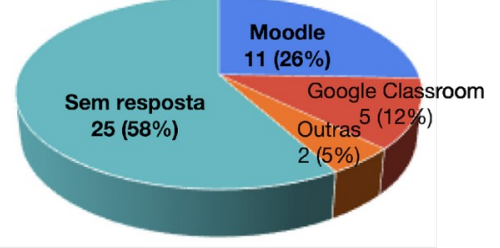

\section{Privadas, Confessionais e S}

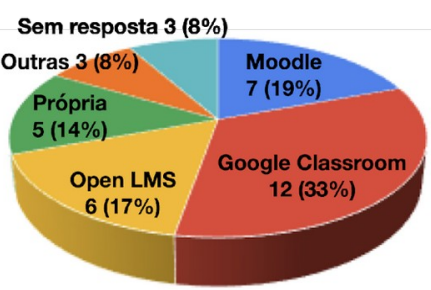

\section{RECURSOS}

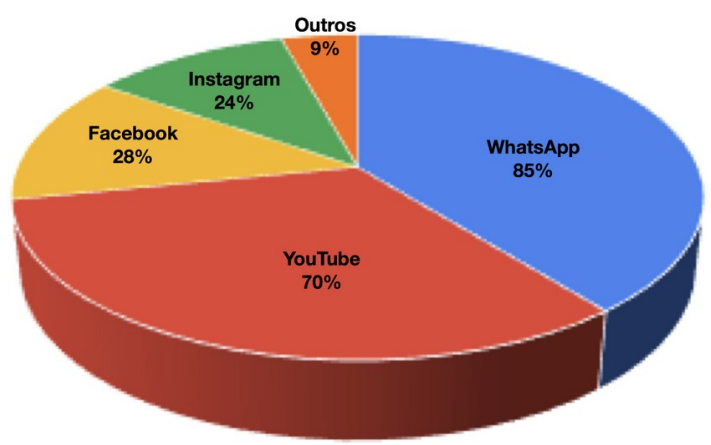

Fonte: Autores deste estudo

O Moodle $(23 \%)$ e o Google Classroom (22\%) foram as principais plataformas utilizadas, sendo que o Moodle foi mais utilizado nas escolas públicas e o Google Classroom nas outras escolas. Entretanto, dentre as que se encontravam em atividade, $85 \%$ indicaram o WhatsApp como recurso mais utilizado e em seguida o Youtube. Inferese que esses recursos foram mais utilizados por serem mais próximos do cotidiano dos usuários e por não apresentarem dificuldade para acesso.

Em relação à condução das aulas, cerca de $75 \%$ das instituições realizavam as atividades de forma síncrona, e a principal ferramenta utilizada para ministrar as aulas online foi o Google Hangout Meet com $57 \%$, Youtube com $22 \%$, Zoom com $21 \%$, Teams com 19\% e Big Blue Button com 8\%, conforme apontado no Gráfico 4. 
Gráfico 4 - Tipo de atividades propostas para a condução das atividades e ferramentas utilizadas nas aulas on-line

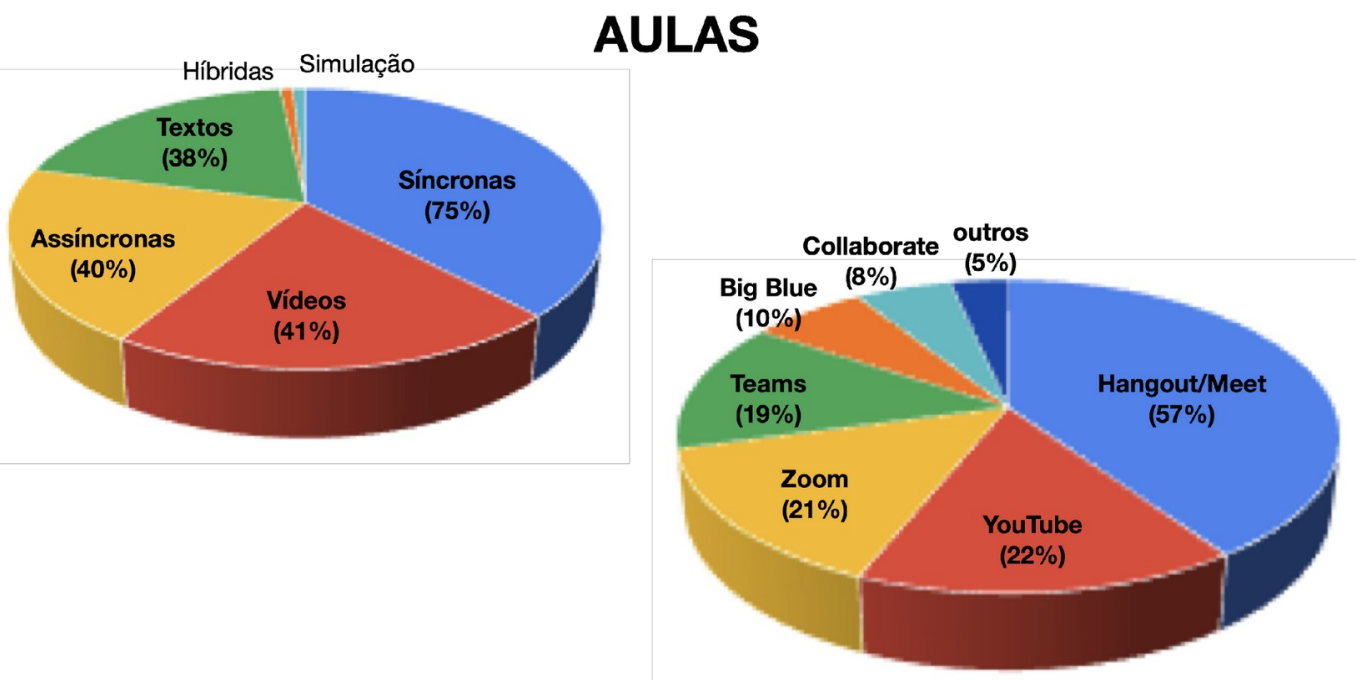

Fonte: Autores deste estudo

Por sua vez, em relação às dificuldades apresentadas quando da retomada das atividades, $76 \%$ apontaram a preparação dos professores e $97 \%$ indicaram o acesso dos discentes no formato de ensino remoto emergencial, o que pode ser analisado frente a outros resultados a partir do Gráfico 5.

Gráfico 5 - Principais dificuldades encontradas durante a retomada de atividades

\section{DIFICULDADES}

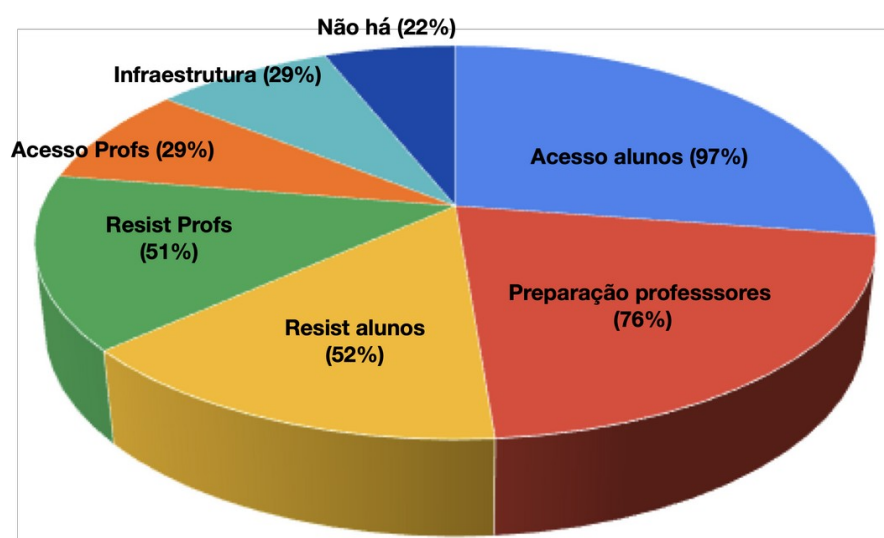

Fonte: Autores deste estudo

Quando questionados sobre a capacitação dos professores, $73,2 \%$ indicaram que ela ocorreu de forma emergencial tendo como foco, em sua maioria, a aprendizagem técnica das ferramentas novas utilizadas, conforme pode ser observado no Gráfico 6. 
Gráfico 6 - Ocorrência e tipo de capacitação

\section{CAPACITAÇÃO DE PROFESSORES}
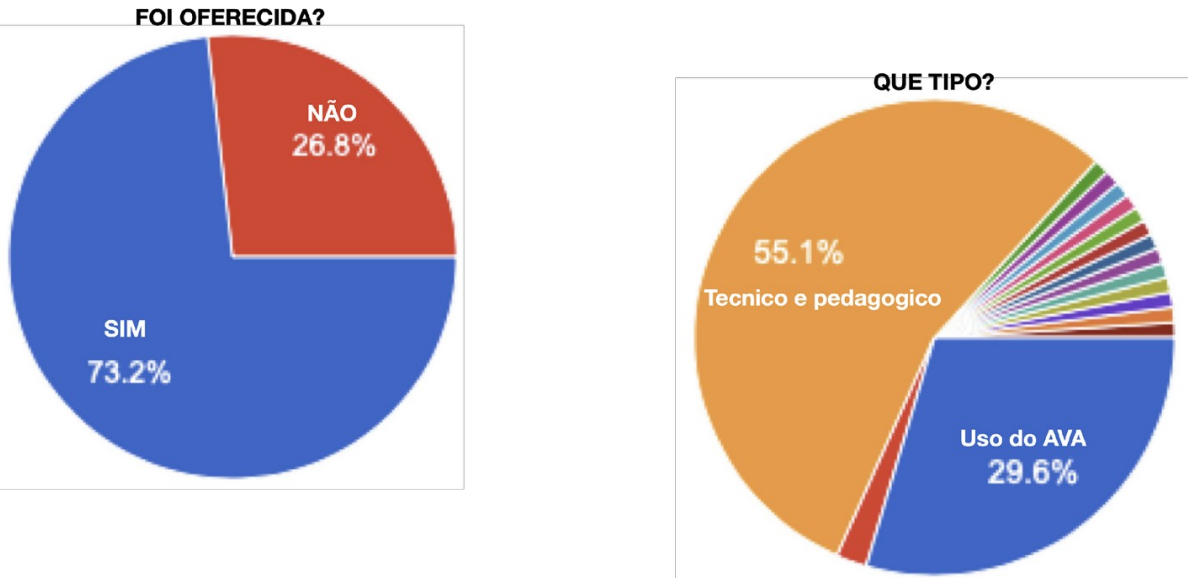

Fonte: Autores deste estudo

Ainda sobre a capacitação, $85 \%$ informaram que a equipe interna da instituição a realizou (Gráfico 7). Entende-se que, considerando o novo contexto e diante de tantas incertezas, a principal (talvez única, em certo período de tempo) alternativa foi realizar as capacitações de forma interna, levando em conta os recursos disponíveis e conhecidos até então.

Gráfico 7 - Quem ministrou a capacitação

Quem ministrou?

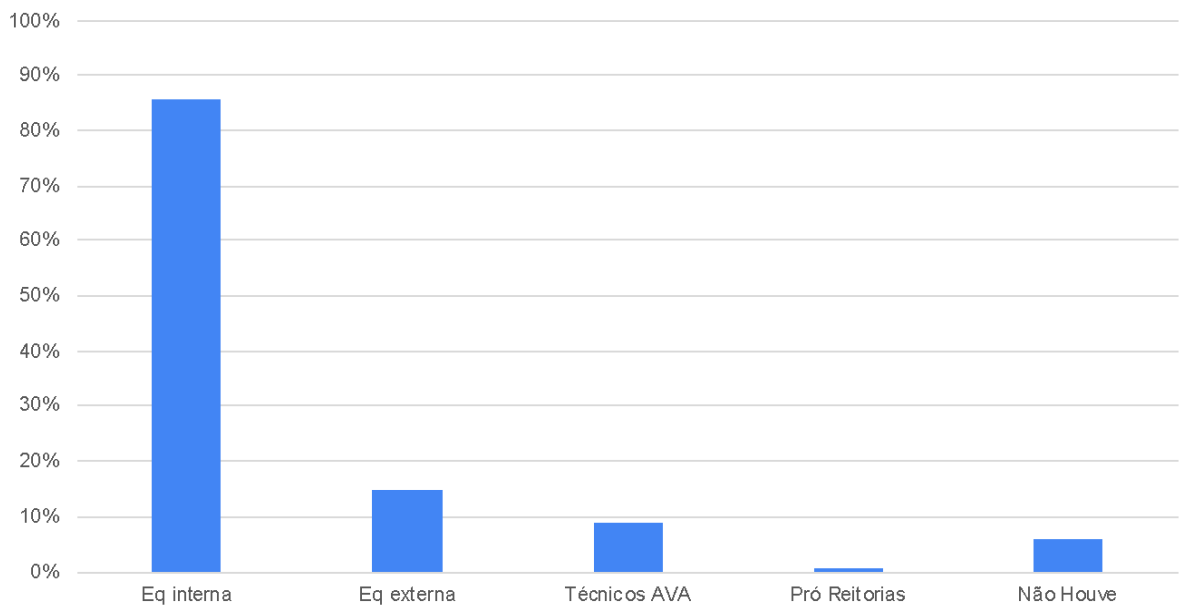

Fonte: Autores deste estudo

Quanto à produção de materiais para uso nas aulas remotas, as apostilas não foram a principal opção, haja vista que os vídeos chegaram à incidência de quase $60 \%$ (Gráfico 8). Possivelmente por demandar mais facilidade de entendimento, os vídeos tiveram mais adesão para uso nas aulas remotas. Além disso, considerando o atual contexto, infere-se que os materiais produzidos também apresentavam tutoriais para uso de ferramentas em aulas remotas uma vez que as aulas assíncronas foram muito desenvolvidas. 
Gráfico 8 - Tipos de materiais produzidos

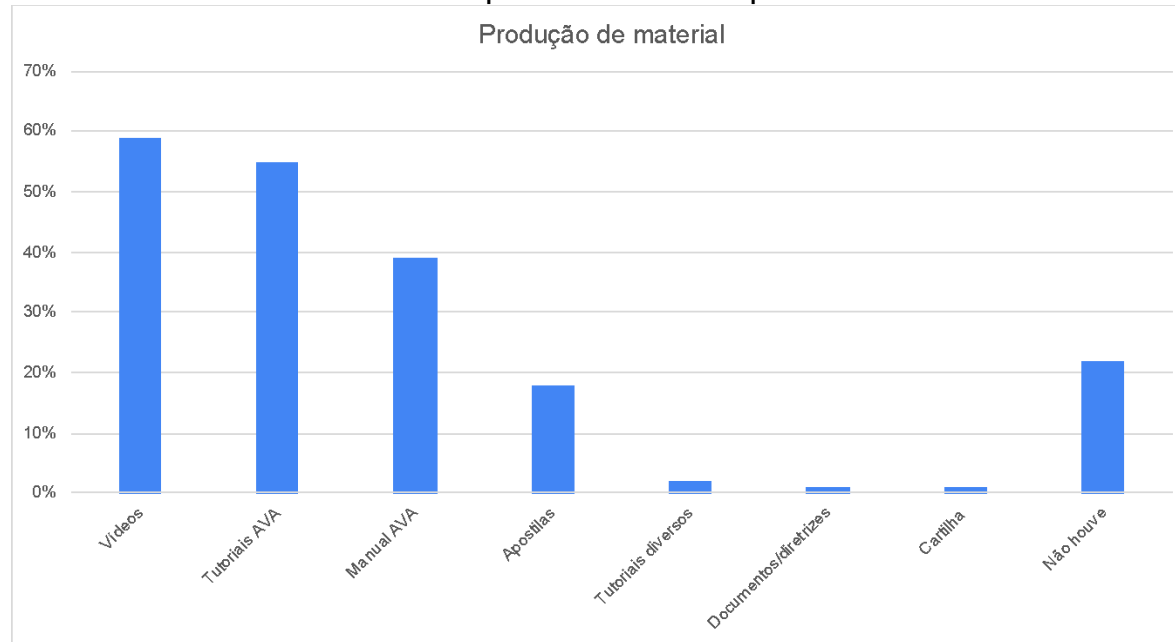

Fonte: Autores deste estudo

Por fim, quando questionados sobre a continuidade das capacitações após a pandemia, ou seja, se as capacitações continuariam com a retomada das aulas presenciais, $37,6 \%$ responderam positivamente a isso, indicando que existe um programa de formação, ao passo que $32,7 \%$ mencionaram haver um processo de construção desse tipo de formação (Gráfico 9).

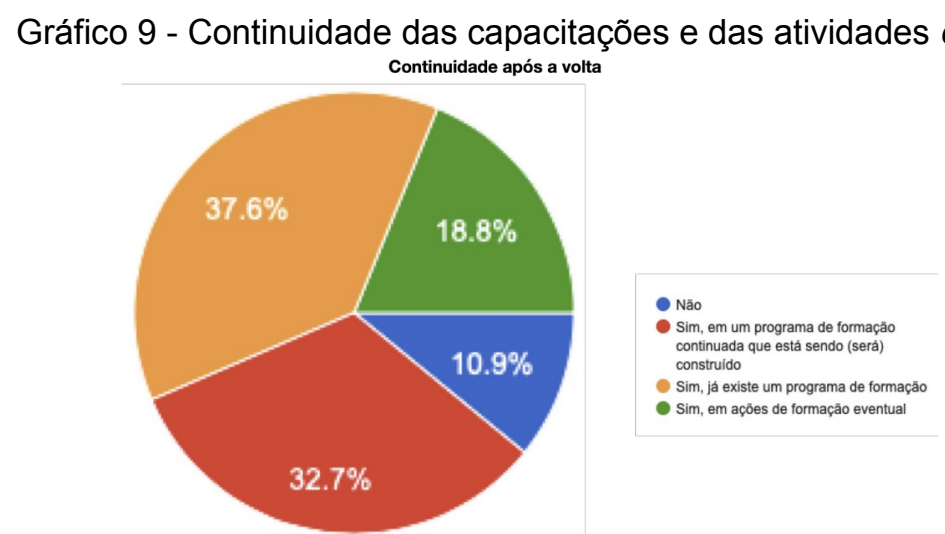

Fonte: Autores deste estudo

Por sua vez, em relação às atividades on-line, o Gráfico 10 ilustra um diferencial para a prática docente, consequência da pós-pandemia.

Gráfico 10 - Continuidade das atividades on-line ACÕES ON LINE VÃO CONTINUAR?

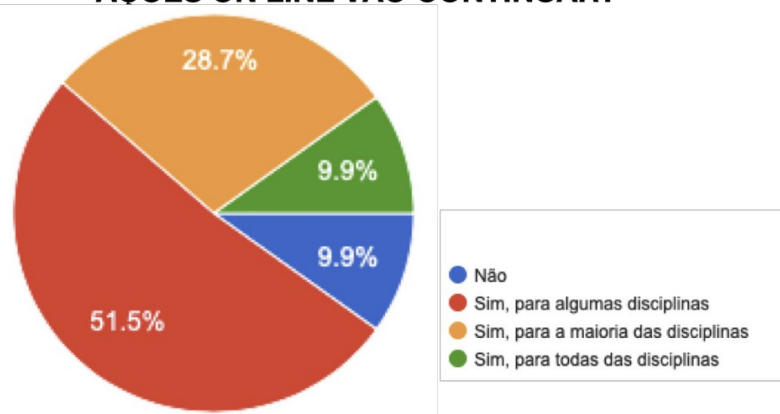

Fonte: Autores deste estudo 
Percebe-se a permanência das atividades on-line com a volta presencial, sendo que $51,5 \%$ manterão as atividades on-line para algumas disciplinas e $28,7 \%$ para a maioria, enquanto $9,9 \%$ para todas as disciplinas. Encontram-se estabelecidos, dessa forma, pontos positivos para a modalidade híbrida de ensino.

\section{$5 \quad$ CONSIDERAÇÕES FINAIS}

O levantamento realizado por este estudo expôs que a maioria das IES respondentes retomou as atividades utilizando várias plataformas e recursos, além de promover alguma forma de capacitação pedagógica e técnica. Como os principais problemas detectados, cerca de $76 \%$ apontaram a preparação dos professores e $97 \%$ indicaram o acesso dos alunos no formato de ensino remoto emergencial.

As IES conduziram suas atividades na maioria de forma síncrona utilizando o Google Hangout Meet como principal ferramenta e em seguida o Youtube, Zoom e o Teams. Foi constatado que boa parte das instituições tem programas de capacitação de docentes $(37,6 \%)$ ou outra boa parte está desenvolvendo um programa $(32,7 \%)$.

A pesquisa identificou também que cerca de $90 \%$ das IES vão incorporar algumas das ferramentas e atividades on-line no novo contexto pós-pandemia. Isso indica que a pandemia trará mudanças significativas no processo de ensino e aprendizagem, o que será verificado quando a segunda etapa deste estudo estiver concluída.

Certamente a educação e o mundo, após esse período de pandemia, não serão os mesmos. Percebe-se que alguns professores, inicialmente resistentes ou tímidos a qualquer diversidade no uso pedagógico das tecnologias, viram-se desafiados para a mudança e agora estão menos resistentes e visualizam possibilidades e ressignificação de suas práticas. O que se espera é o aprofundamento das discussões sobre as mudanças necessárias, e a formação continuada se torne elemento fundamental para os espaços de estudo.

\section{REFERÊNCIAS}

AZEVEDO, Gabriela; MATTASOGLIO NETO, Octavio; FONSECA, Thais Bagatim. Engajamento do professor em home-office devido ao súbito isolamento provocado pela pandêmica do Covid-19. In: CONGRESSO BRASILEIRO DE EDUCAÇÃO EM ENGENHARIA, 58.; SIMPÓSIO INTERNACIONAL DE EDUCAÇÃO EM ENGENHARIA DA ABENGE, 3., 2020, [s. I.]. Anais [...]. [S. I.]: UCS, 2020. DOI 10.37702/COBENGE.2020.3301. Disponível em: . Acesso em: 7 maio 2021.

HOBOLD, Márcia de Souza; MATOS, Sílvia Simão de. Formação continuada: o processo de incorporação das novas tecnologias de informação e comunicação no trabalho do professor universitário. Rev. Diálogo Educ., Curitiba, v. 10, n. 30, p. 317-333, maio/ago. 2010. Disponível em:

https://periodicos.pucpr.br/index.php/dialogoeducacional/article/download/2437/2347. Acesso em: 7 maio 2021.

KUHFELD, Megan et al. Projecting the Potential Impact of COVID-19 School Closures on Academic Achievement. Educational Researcher, [s. I.], v. 49, n. 8, p. 549-565, November 2020. DOI 10.3102/0013189X20965918. Disponível em: 
https://journals.sagepub.com/doi/pdf/10.3102/0013189X20965918. Acesso em: 8 maio 2021.

MISLEH, Soraya. Desafios à educação em engenharia hoje e no pós-pandemia. Seesp, São Paulo, 25 jun. 2020. Disponível em:

https://www.seesp.org.br/site/index.php/comunicacao/noticias/item/19342-desafios-aeducacao-em-engenharia-hoje-e-no-pos-pandemia. Acesso em: 5 out. 2020.

NAKAO, Osvaldo Shigueru; GRIMONI, Jose Aquiles Baesso. O atendimento às DCNs de 2019 em uma disciplina durante a pandemia de 2020. In: CONGRESSO BRASILEIRO DE EDUCAÇÃO EM ENGENHARIA, 58.; SIMPÓSIO INTERNACIONAL DE EDUCAÇÃO EM ENGENHARIA DA ABENGE, 3., 2020, [s. I.]. Anais [...]. [S. I.]: UCS, 2020. DOI 10.37702/COBENGE.2020.3278.

NHANTUMBO, Telma Luís. Capacidade de resposta das instituições educacionais no processo de ensino-aprendizagem face à pandemia de covid-19: impasses e desafios.

Revista EDUCAmazônia, Educação, Sociedade e Meio Ambiente, Humaitá, v. 25, n. 2, p. 556-571, jul./dez. 2020. Disponível em:

https://periodicos.ufam.edu.br/index.php/educamazonia/article/view/7851/5535. Acesso em: 28 set. 2020.

\title{
DIDACTIC-ADMINISTRATIVE ACTIONS DURING PANDEMIC: RESULTS OF THE RESEARCH OF THE ABENGE TEACHER TRAINING WORKING GROUP
}

\begin{abstract}
This study presents the results of the research carried out by the Abenge Teacher Training Work Group on how higher education institutions acted during the suspension of face-to-face activities due to the pandemic. 79 institutions responded to the survey, being 33 federal public universities, 8 state public universities, 12 confessionals, 25 private institutions and 1 of the $S$ System. As a main result, it was identified that the institutions adapted to the new context through the use of platforms and differentiated tools focused on the development of didactic-administrative activities.
\end{abstract}

Keywords: Teacher Training. University Education. Remote Teaching. Lifting. Technology-mediated Education. 